\title{
Empowerment: Doctor vs Nurses
}

\author{
Silvia Akter ${ }^{1}$
}

${ }^{1}$ Faculty of Business, East West University, Bangladesh

\begin{abstract}
This paper aims to see the levels of empowerment exist in the private hospital in Dhaka city, considering the case of doctors and nurses. A small sample of 40 respondents from the two private hospitals was chosen randomly. The theories of empowerment are discussed and the results are analyzed in respect to the theories which shows that doctors are more empowered than the nurses.
\end{abstract}

Keywords: Empowerment, leadership, Hospitals, Motivation JEL Classification Code: M10

\section{INTRODUCTION}

$\mathrm{T}$ HE The issue of empowerment has gained a lot of attention by both academics and managers since its adaptation at work place in 1990's.In order to gain competitive advantage organisations needs to be more agile, keep their cost low and increase value to the customers. To tackle with all these issues organizations have realised that their main assets are their employees. Empowerment as per official definition is simply giving the power to make their voice heard, allow them to contribute to plans and decisions that help to improve their performance and eventually the performance of your whole organisation (Foy, 1994). As mentioned by many scholars employee empowerment hold a very important place in today's global business environment. Employee empowerment involves approaches that can be applied universally by all organizations to improve there services and in return can attain higher returns from their inputs. But at the same time even though a lot of research has been carried out on employee empowerment it is still a topic that is in its infancy (Dimitriades, 2005).

The present study considers the issue of empowerment in the health care sector.

Hyman and Cunningham (1996) are considered to be one of the main contributors in the field of studying empowerment in health sector. The work presented by them indicates that due to an increase competition in health care sector, employee empowerment is crucial in total quality management and customer care. It is a key of improving commitment, performance and staff motivation. The paper examines the extent of employee empowerment in private health care sector in Dhaka.

\section{ConCEPTS OF EMPOWERMENT}

The phenomenon of empowerment has been gaining a lot of importance in today's organizational environment and it is estimated that more then 70 percent of organizations have introduced some kind of empowerment in their working environment. Ward and Wilcox (1999) explain empowerment as it relies on the concept of delega-

tion, but there is a difference between empowerment and delegation. Although the term empowerment has no agreed upon definition, we will consider empowerment as "the process in which employees are given increasing amounts of autonomy and discretion in connection with their work" (Greenberg and Baron, 2003). Foy (1994) shared her findings on empowerment as "it is simply gaining the power to make your voice heard, to contribute to plans and decisions that affect you, to use your expertise at the work to improve your performance-and with it the performance of your whole organization".. There are a lot of popular books, articles and other material on explaining the phenomenon of empowerment, Menon (2001) discusses the work of Tymon (1988) who conceptualized employee empowerment literature in to three major categories: (a) the Social-structural approach, (b) the motivational approach, and (c) the leadership approach. These approaches presented by Tymon (1988) clearly showed the diversity of thinking on empowerment. Dimitriades (2005) also supported the work of Menon (2001) and explains that the "Empowerment has been considered an act: the act of granting power to the person(s) being empowered. It has been considered a process: the process that leads to the experience of power. It has also been considered a psychological state that manifests itself as cognitions that can be measured".

\subsection{Social-Structural Empowerment}

The study of Social-structural approach is still a developing field and the roots of it have been derived from the theories of social exchange and social power (Rogelberg, 2006). Social- structural empowerment means organizations structure, policies and practices that grant greater opportunity to make decisions and apply influence regarding their work (Greasley et al, 2008). In this perspective power is shared from top to bottom level hierarchy equally creating a democratic organization where formal authority, control on resources and ability to make decisions related to ones job or their role. Manojlovich (2007) in her article discusses Kanters' work on structural em- 
powerment and the theory presented by is called "theory of structural empowerment". The theory talks about opportunity and power as it should be available to the entire employee for a maximum organizational effectiveness and success. Laschinger questionnaires show the association of the following factors such as "access to information, resources, support, and opportunity in their work environment are important determinants of collective accountability and their ability to be effective in their work" (Timothy Porer-O'Grady, 2009). Bailey (2009) criticizes the theory in that it lacks the multi-level aspects of modern organizations; therefore an additional work is needed in order to understand the complex nature organizations. (http://www.dhbailey.com/papers/dhbpostmodern.pdf)

\subsection{Motivational/Psychological Empowerment}

Empowerment in terms of motivational construct depends on the understanding of empowerment through individual internal need and control and feeling of personal efficacy (Lashley, 2001). The concept of motivational empowerment according to some authors is also known as psychological empowerment. Conger and Kanungo (1988, pg471) are considered to be the pioneers in developing the concept of motivational empowerment and they have conceptualized empowerment as psychological enabling. Thomas and Veltouse (1990) using motivational empowerment describes empowerment "as an intrinsic task motivation reflecting a proactive, rather than passive, orientation to ones work role" (Sagie and Koslowsky, 2000). The concept of psychological empowerment moves away from a traditional study of management practice and talks about the perception and experience from employee perspective.

\subsection{Leadership Empowerment}

The concept of leadership empowerment has drawn heightened attention by many authors in recent years and the focus on leadership studies has shifted from traditional views to new modern theories. A traditional organizational is considered to be where there is hierarchical structure, top down philosophy of control and centralized decision making and in such organizations leadership styles cause employees a sense of powerlessness (e.g. bureaucracy) in utilizing their productivity and creativity and resulting in poor overall performance. And the process of changing or removing the factors that leads to powerlessness, it is expected that employees will perform well with maximum potential and will also allow them to sustain it, has been popularly referred as empowerment (Thomas and Velthouse, 1990). Many authors have emphasis on the energizing aspect of empowerment and explains leadership approach as it a process of energizing employees (Menon, 2001). Honold (1997) discusses the significance of leaders and how their role contributes in distributing power. Leadership approach is built on trust as it is the basis that binds follower to the leader and an empowered organization is where leaders or managers administer more people then in traditional hierarchy and delegate decision powers to subordinates. When leaders transfer responsibility to their subordinates, in return they feel more satisfied with their superiors and perform activities according to their expectations (Keller and Dansereau, 1995).

\section{Aims/ObJectives}

To examine the impact of employee empowerment in Private Health Service in Dhaka and to understand the issues and barriers in related to introducing employee empowerment in NHS.

\section{Methodology}

The research is based on primary and secondary data. Secondary data is based on books, journals, related articles and topics on empowerment. Where as the primary research is conducted by choosing a quantitative method, where closed end questionnaires have been used. A pilot test method has been used just to see the reliability of the questionnaires. The data obtain then have been analysed and the results have been discussed in related to the theories and the work of authors discussed on the literature review. 40 questionnaires were distributed in two private hospitals by using a random sample technique which helped in carrying out the statistical analysis.

\section{FINDINGS \& DISCUSSION}

Majority of the respondent were male $(70 \%)$ and the rest were female. This shows lower level of participation of female in health practices. Among the male respondents most of them are physicians and upper level management staff and among the female majority of them were nurses.

There were no separate questionnaires used in the survey but after getting the data from the filled out questionnaires and analysing them respondents have been divided into two categories. One is nurses who are considered in the survey as front line employees and are responsible and accountable for a day-to-day interaction with the patients, the second category is of doctors (who also are a part of front line employees and responsible for day to day interaction with the patients) and management Staff. Data shows that out of 40 participants $7.4 \%$ answered between $0-1$ years, $22.2 \%$ answered between 12 years, $11.1 \%$ answered between $3-5$ years and $14.8 \%$ answered 6 years and above.

Majority of the respondents from the nurses category disagreed with the statement that they are always consulted by the supervisors before any change to their job brought by the management showing very lower level of empowerment on part of the subordinate staff(nurses). On the contrary majority of the respondents belonging to physician/staff category agreed with the statement that they are being consulted by the administration before redesigning any aspect of their job. These results showed that nurse and others enjoy very lower level of empowerment but people holding superior position have higher level of empowerment. 
In responding to he question whether respondents can Influence decisions that are taken the respective departments, data illustrates again that majority of employees i.e. nurses gave the answer in a negative way which is that by disagreeing they confirm that there exist no power in influencing any decision process in the department whereas their superior counterparts agreeing with the statement very strongly.

It can be said from the above discussion is that the front line employees (Nurses) have a very little involvement when it comes to making or influencing any decision that are taken in their work or job role. With no presence of decision making or influencing power the findings above go against with the concept of social-structural empowerment as discussed in the literature review, which talks about granting power to an individual in a decision making or in influencing process. As the evidence from the above discussion and data shows contradiction with the social-structural empowerment and shows the presence of non- democratic along with none power sharing culture it indicates to the point raised by Manojlovich (2007) work based on Kanters' theory known as "theory of structural empowerment" that only with the existence of power and opportunity an individual would be able to give its maximum out put and thus resulting a maximum contribution towards work effectiveness and success.

The findings also clearly indicates that managers possess majority of decision making and influencing power and the involvement of font line employees (Nurses and Doctors) is less as compared to them. This shows that there is structural factor involved and does not allow lower level or sub ordinates working under them to take much involvement. This really shows that the power has a shift more towards the employees who are on a managerial level and there exists a structural barrier. So in the absence of power sharing culture the finds are going against Greasley et al., (2008) who has described a democratic organization as where the flow of power is from top to bottom making an environment where one can make and bring changes in accordance to their job role. From both the doctors and nurses category $40 \%$ strongly agree and 53.3 agree regarding a question about motivation signalling that both the group are highly motivated about their job.

Again in another quarry majority $(80 \%)$ of the nurses responded negatively to the statement that they in have considerable amount of autonomy their job roles though the doctor group responded positively towards this statement. It can be concluded from the above discussion is that majority of employees who participated in the survey showed that they are highly motivated in their work. This shows that private hospitals have a culture that has a high level of motivational environment where everyone feels motivated whilst performing their job roles. By taking in account that motivation exists in hospitals it can be also be said that the physiological empowerment as described by Conger and Kanungo (1988) also influence the employees to do their best at work.

As showed above that the nurses have lower degree of autonomy as compared to the doctors. It means that lower level of employees have less autonomy compared to the higher level of the management. By combining the level of motivation and amount of autonomy, it can be said that the doctors are in better position in respect to empowerment than the nurses. The doctors results match with Lee and Koh (2001)'s "Cognitive model of empowerment" which mentions that empowerment can only be achieved in the presence of four factors i.e. sense of meaning, self-efficacy, self-determination(autonomy) and impact, and with missing of even one factor will hinder empowerment. The doctors sample have almost all these four factors but none exists in Nurses therefore making empowerment only exists in doctors not for both.

However, nurses along and doctors as well may be termed as empowered in line of the argument of Conger and Kanungo (1988) which identifies motivation, as the basis of psychological empowerment as both the group showed high level of motivation. It is revealed from the survey that front line employees are motivated but not all of them have high level of autonomy.

The above discussion and findings therefore shows there exists empowerment in relates to Conger and Kanungo work but if we look and Lee and Koh (2001) work they are not empowered because empowerment does not come just from one factor it is a result of combination of different factors. This indicates that Conger and Kanungo work is very limited and although the work has been used and enhanced by many authors but still more work is needed, Lee and Koh (2001) work is more refined and reliable as it covers other areas from which empowerment can be effected.

As from the above discussion and graphs it has been seen that motivation is at a higher level in NHS. If we discuss this motivation in the light of work presented by Yagil (2006) as discussed in the literature review we can presume that high level of motivation will bring stress and burnout among the NHS employees which will affect the performance level. So as suggested by the findings of Yagil (2006) to deal with the situation motivation must be dealt by introducing empowerment. Since the results and discussion above indicated that only the top level that are managers are experiencing empowerment as they have more power/autonomy as compared to the front line employees, excessive motivation will not only show a negative affect on management level but will also affect in a negative way to the front line staff as there exists no empowerment leaving them with no power to cope with the situation.

Data analysis shows that the majority $(80 \%)$ front line employees (nurses) pointed out that the managers or supervisors have the edge in respect to power and nearly all the decision are taken by the managers.

Interestingly, majority $(54 \%)$ of the employees are undecided about the motion whether they are happy with their managers or not, while $27.3 \%$ are unhappy and only $18.2 \%$ are happy with their managers. It included sentiments of both the employee groups, i.e. doctors and nurse. 
The discussion above points out to the work carried out by Thomas and Velthouse (1990) as mentioned in the literature review. The survey shows private hospitals is still operating on a tradition organizational structure where there is a tight control over decision making and leaders makes employees powerless rather then making them empowered. By looking at the work of Honold (1997) and Keller and Dansereau (1995) in the literature review, their findings emphasises on the importance of leaders and its qualities. Analysing the results of this study in accordance with the work of Honold (1997) and Keller and Dansereau (1995), its is clearly seen that private hospital leaders do not possess qualities as explained by the authors. Since there are no leadership qualities there will be no job satisfaction, which eventually will result in disempowerment in the organizations.

\section{Conclusions}

The findings of the study in relation with structural empowerment shows the evidence that private hospitals in Dhaka is still operating on a traditional structural style where individuals are not being involved in decision making process which making them disempowered. By studying the work of different scholars it has been noticed that although a great importance has been given to the concept of motivation but it has also been advised to use a careful approach as discussed in the literature review the work of Yagil (2006) who's findings clearly shows excessive motivation can result in job stress and emotional exhaustion but empowerment can help in coping with all these issues.

The results then are studied and it is found that participated health care employees have a high level of motivation but when it comes to the self determination or autonomy the results are changed as majority of nurses answered saying that they don't have the autonomy, while the doctors show signs of both motivation and self determination making them more empowered as compared to the nurses. This indicated towards the work of Lee and Koh (2001) who has mentioned that empowerment is not caused by a single factor it is a combination of different factors acting together in attaining empowerment. The third empowerment factor discussed and analysed in the research is the leadership empowerment. The findings from the data points out that as compared to doctors, nurses are not so much satisfied indicating that if there is any work related problems not much importance is given to them and are not being solved.

\section{REFERENCES}

[1] Conger, J, A. and Kanungo, R, N. (1988), 'The Empowerment Process: Integrating Theory and Practice, Academy of Management Review, 13(3), 471-482.

[2] Cox, P, L (2001) Transformational Leadership: A Success Story at

[3] Dimitriades, S. Z, (2005), 'Employee Empowerment in the Greek Context', International Journal of Management, 26(1), 80-92.
[4] Foy, N. (1994) Empowering People at Work, England: Gower.

[5] Greasley, K. Bryman, A. Dainty, A. Price, A. Naismith, N and Soetanto, R. (2008), 'Understanding Empowerment from an Employee Perspective: What does it mean and do they want it? Team Performance Management, 14(1/2), 39-55).

[6] Greenbery, J. and Baron, A, Robert. (2003) Behaviour in Organizations, 8th edition, Harlow: Prentice Hall.

[7] Greenberg, J. and Baron, R. (2003), Behavior in Organizations, Pearson Education, Inc. Upper Saddle, NJ

[8] Honold, L. (1997), 'A Review of the Literature on Employee Empowerment', Empowerment in Organization, 5(4), 202-212.

[9] Hyman, J. and Cunningham, I. (1996), 'Empowerment: The Right Medicine for Improving Employee Commitment and Moral in the NHS?', Health Manpower Management, 22(6). 14-24.

[10] Keller, T. and Dansereau, F. (1995), "Leadership and empowerment: a social exchange perspective," Human Relations, Vol. 48(2), 127-46.

[11] Lashley, C. (2001) Empowerment: HR Strategies for Service Excellence, Oxford: Butterworth Heinemann.

[12] Lee, M and Koh, J ( 2001), Is Empowerment Really a New Concept, International Journal of Human Resource Management, Vol. 12, No. 4, pp-684-95

[13] Manojlovich, M. (2007), 'Power and Empowerment in Nursing: Looking Backward to Inform the Future', Power and Empowerment in Nursing, The online Journal of Issues in Nursing, (viewed on $4 / 03 / 2010$

at www.nursingworld.org/MainMenuCategories/ANAMarketplace/A NAPeriodi-

cals/OJIN/TableofContents/Volume122007/No1Jan07/LookingBack wardtoInformtheFuture.aspx).

[14] Menon, R. (2001), 'Employee Empowerment: An Integrative Psychological Approach', Applied Psychology: An International Review, 50(1), 153-180.

[15] Rogelberg, G, S. (2006) Encyclopaedia of Industrial and Organizational Psychology, CA: Sage.

[16] Sagie, A. and Koslowsky, M. (2000) Participation and Empowerment in Organization: Modelling, Effectiveness, and Applications, England: Sage.

[17] Thomas, K. W. and Velthouse, B. A. (1990) "Cognitive Elements of Empowerment: An 'Interpretive' Model of Intrinsic Task Motivation". Academy of Management Review, Vol 15, No. 4, 666-681.

[18] Porter-O'Grady, Tim (2009). Interdisciplinary Shared Governance: Integrating Practice, Transforming Health Care. USA:Jones \& Barlett Publishers.

[19] Tymon, W. G. (1988). An Empirical Investigation if A Cognitive Model Of Empowerment. Unpublished Doctoral Dissertation, Temple University, Philadelphia

[20] Willcocks, S. (2008), 'Clinical Leadership in UK Health Care: Exploring a Market Perspective', Leadership in Health Services, 21(3), 158-167.

[21] Yagil, D. (2006), 'The Relationship of Service Provider Power Motivation, Empowerment and Burnout to Customer Satisfaction', International Journal of Services Industry Management, 17(3), 258-270

[22] Ward, Michael E. and Wilcox Bettye MacPhail (1999), Delegation and Empowerment: Leading With and Through Others, Eye on Education, NY. 